\title{
Clinical characteristics and immunological abnormalities of Castleman disease complicated with autoimmune diseases
}

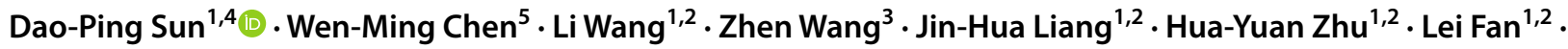 \\ Yu-Jie Wu ${ }^{1,2} \cdot$ Wei $\mathrm{Xu}^{1,2} \cdot$ Jian-Yong $\mathrm{Li}^{1,2}$
}

Received: 15 November 2020 / Accepted: 2 December 2020 / Published online: 5 February 2021

(c) The Author(s) 2021

\begin{abstract}
Purpose To explore the clinical features and immunological mechanisms of Castleman disease (CD) complicated with autoimmune diseases (AID).

Methods We explored the prevalence and clinical manifestations of CD complicated with AID by reviewing clinical, pathological, and laboratory data of $40 \mathrm{CD}$ patients retrospectively, and then explored abnormal immune mechanisms in the co-existence of the two entities by monitoring lymphocyte subsets in peripheral blood.

Results Paraneoplastic pemphigus, autoimmune hemolytic anemia, Sjogren's syndrome, myasthenia gravis, and psoriasis were found to be coexisted with CD in $9 / 40$ (22.5\%) patients with different sequence of onset. No bias in the clinical and histological type of CD was observed for the occurrence of AID. CD patients with AID were more likely to have skin and/or mucous membrane damage and pulmonary complications, and presented elevated erythrocyte sedimentation rate, hypergammaglobulinemia, and positive autoantibodies than those without AID $(p<0.05)$. Deregulated cellular and innate immune responses as indicated by decreased $\mathrm{CD}^{+} \mathrm{T}$ cells and increased natural killer cells were observed in peripheral blood of CD patients with AID $(p<0.05)$. UCD patients with AID were successfully treated with surgery and immunosuppressive therapy. MCD complicated by AID relieved with immunosuppressors, cytotoxic chemotherapy, and rituximab.

Conclusion Systemic inflammation/immunological abnormalities and organ dysfunction were associated with the occurrence of AID in CD. Impairment of cellular and innate immunity may be a candidate etiology for the coexistence of the two entities.
\end{abstract}

Keywords Castleman disease $\cdot$ Autoimmune diseases $\cdot$ Immunological abnormalities $\cdot \mathrm{T}$ cells $\cdot$ Natural killer cells

\section{Introduction}

Wei Xu

xuwei10000@hotmail.com

$\triangle$ Jian-Yong Li

lijianyonglm@126.com

1 Department of Hematology, The First Affiliated Hospital of Nanjing Medical University, Jiangsu Province Hospital, Nanjing 210029, China

2 Pukou CLL Center, Nanjing 210000, China

3 Department of Pathology, The First Affiliated Hospital of Nanjing Medical University, Jiangsu Province Hospital, Nanjing 210029, China

4 Department of Hematology, Jining No. 1 People's Hospital, Jining 272011, China

5 Department of Oncology, Jining No. 1 People's Hospital, Jining 272011, China
Castleman disease (CD) represents a group of disorders characterized by polyclonal B lymphocyte proliferation, often associated with autoimmune manifestations, and occasionally be complicated with autoimmune connective tissue disease, such as systemic lupus erythematous (SLE), rheumatoid arthritis (RA), Sjogren's syndrome (SS), mixed connective tissue disease, autoimmune hemolytic anemia (AIHA), myasthenia gravis (MG), amyloidosis, or thrombotic thrombocytopenic purpura (Muskardin et al. 2012; Wang et al. 2018; Ben-Chetrit et al. 1989; Lee et al. 2012; Yuzuriha et al. 2011; Tabata et al. 2019; Dei-Adomakoh et al. 2018; Ishikawa et al. 2014; Ogita et al. 2007; London et al. 2017). In addition, CD is related to the pathogenesis of paraneoplastic pemphigus (PNP) which is characterized by autoimmune-mediated cutaneous lesions with concomitant occurrence of either occult or confirmed systemic neoplasm (Bin et al. 2019). CD should be suspected 
when there is a change in features of a patient's autoimmune disease (AID), or when the AID is unusually challenging to treat (Muskardin et al. 2012). However, due to limited numbers of case reports and studies on CD and associated AID, lack of profound understanding and extensive attention on the coexistence of these two entities may confound the clinical picture, resulting in delayed diagnosis and suboptimal treatment. Early identification of CD could be challenging, particularly in patients with AID that frequently manifest with lymphadenopathy (Muskardin et al. 2012). In-depth understanding of the prevalence and clinical manifestations of CD complicated with AID will be helpful to make an early and timely diagnosis.

The associations of CD with AID have not been fully illustrated. Autoimmune manifestations and autoantibodies are frequently found in CD patients without a definitive autoimmune diagnosis (Fajgenbaum et al. 2014; Liu et al. 2016). In reverse, several autoimmune disorders, such as SLE and RA, could present disseminated lymphadenopathy with histopathological findings compatible with CD (Kojima et al. 2000, 2006). These suggest that they likely share same features of pathophysiology. $\mathrm{CD}$ is an atypical lympho-proliferative disorder accompanied by severe chronic inflammatory responses (Fajgenbaum and Shilling 2018). B cells in germinal centers of hyperplastic lymph node continuously produce excessive interlukin-6 (IL-6), and this cytokine is responsible for the variety of clinical symptoms and laboratory abnormalities in patients with this disorder (Fajgenbaum and Shilling 2018; Yoshizaki et al. 2018). IL-6 may also be responsible for autoimmune phenomena associated with $\mathrm{CD}$, by inducing expansion of autoantibody-producing $\mathrm{CD}^{+} \mathrm{B}$ lymphocytes (Muskardin et al. 2012). In reverse, autoantibodies may stimulate antigen-presenting cells in the lymph node to release more proinflammatory cytokines, resulting in exacerbation of CD symptoms (Fajgenbaum et al. 2014). However, it should be noted that, other cytokines and impairment of cellular immune mechanisms may also favor the development of both AID and CD (Marchi et al. 2004). Evaluation of their shared pathogenesis allows the development of more effective therapies.

In this study, we explored the prevalence and clinical manifestations of CD complicated with AID, and then explored abnormal immune mechanisms in the co-existence of the two entities by monitoring lymphocyte subsets in peripheral blood. Finally, we discussed the treatment and outcomes of CD accompanied by AID.

\section{Methods}

\section{Patients}

A total of 42 cases of histologically confirmed CD, including 22 males and 20 females, with a median age of 42 and a range of 15-80 years, were encountered at the First Affiliated Hospital of Nanjing Medical University between 2012 and 2019. The diagnosis of CD was established by excisional lymph node biopsy in all patients.

\section{Definitions}

For the histopathology diagnosis of $\mathrm{CD}$, microscopic slides from all patients were retrieved from the Pathology Department and reviewed by two pathologists. CD was divided into two major histological types, the hyaline vascular (HV) and plasma cell (PC) type, according to the criteria of Keller et al. (1972). For the clinical diagnosis, CD was divided into unicentric CD (UCD), which involved a single enlarged lymph node or region of lymph nodes and multicentric CD (MCD), which involved multiple lymph node stations (Dispenzieri and Fajgenbaum 2020). MCD is further divided into idiopathic MCD (iMCD), HHV8-associated MCD (HHV8MCD), and POEMS-associated MCD (Dispenzieri and Fajgenbaum 2020).

Among patients with histologically confirmed CD, those who meet full criteria for autoimmune disorders including SS, psoriasis, MG, AIHA, and PNP were diagnosed as AID coexisting with CD (Stefanski et al. 2017; Sève et al. 2008; Kartan et al. 2017; Sehgal and Srivastava 2009; Raychaudhuri et al. 2014; Hehir and Silvestri 2018). As the majority of enlarged lymph nodes from patients with RA and 15-30\% of SLE display MCD-like histopathology, patients with "Castleman-like" histopathological changes who fulfill the criteria for a definitive diagnosis of SLE and RA were excluded from the diagnosis of MCD (Fajgenbaum et al. 2017; Petri et al. 2012; Aletaha et al. 2010). Patients with autoantibodies who do not meet full criteria for a rheumatologic condition and have pathologic features and other criteria consistent with $\mathrm{CD}$ are diagnosed as $\mathrm{CD}$.

\section{Data collection}

A thorough review of systems, physical examination, complete blood count, urinalysis, erythrocyte sedimentation rate (ESR), C-reactive protein (CRP), rheumatoid factor (RF), anti-streptolysin O (ASO), Coombs test, liver function tests, serum creatinine, lactate dehydrogenase, serum immunoglobulin, serum protein electrophoresis with immunofixation, antinuclear antibody (ANA), double stranded antinuclear antibody (ds-DNA), extractable nuclear antigen polypeptide antibodies (ENA), antineutrophil cytoplasmic antibody (ANCA), anticardiolipin antibody (ACA), serology for HBV, HCV and HIV, and CT of chest, abdomen, and pelvis (or PET/CT) were done for all patients. Relevant clinical, pathological, and laboratory data were obtained by reviewing patients' medical records and appropriately 
contacting identified patients by telephone conversations up to August 2019.

\section{Analysis of lymphocyte subsets}

Analysis of peripheral blood lymphocyte subpopulations by flow cytometry was performed at the diagnosis of CD. Peripheral blood samples were collected and stained using the whole blood lysis technique. Phenotypic analyses were performed by flow cytometry using BD multitest CD3/ CD8/CD45/CD4 reagent and CD3/CD16 ${ }^{+}$CD56/CD45/ $\mathrm{CD} 19$ reagent. These antibodies are labeled as follows: PerCP-anti-CD45, FITC-anti-CD3, APC-anti-CD4, PE-antiCD8, APC-anti-CD19, PE-anti-CD16 +CD56 (all from BD Biosciences USA). The percentages of the lymphocyte subsets including $\mathrm{CD}^{+} \mathrm{T}$ cells, $\mathrm{CD} 4^{+} \mathrm{T}$ cells, $\mathrm{CD} 8^{+} \mathrm{T}$ cells, $\mathrm{CD} 19^{+} \mathrm{B}$ cells, and $\mathrm{CD} 3^{-} \mathrm{CD} 16^{+} \mathrm{CD} 56^{+}$Natural killer (NK) cells, as well as $\mathrm{CD}^{+} / \mathrm{CD} 8^{+}$ratio were measured.

\section{Statistical analysis}

Continuous variables are expressed as mean \pm standard deviation (SD) and categorical ones as number of cases (percentage). K-S test was used for normality test. Differences in numerical data were compared by the independent $t$ test or Mann-Whitney $U$ test. Differences in categorical data were compared using the chi-square test or Fisher exact test. Data analysis was performed using SPSS21 statistical software. A value of $p<0.05$ was considered to be significant.

\section{Results}

\section{Prevalence of CD complicated by AID}

Except two patients with "Castleman-like" histopathological changes who fulfill the criteria for SLE and RA, respectively, were excluded from the diagnosis of $\mathrm{CD}, 40$ patients were diagnosed as $\mathrm{CD}$ definitely. Among them, 25 patients were diagnosed with UCD, and 15 patients with MCD, including 13 iMCD, 1 HHV8-MCD, and 1 POEMS-associated MCD. Histological types included $\mathrm{HV}$ in 25 patients, and $\mathrm{PC}$ in 15 patients.

AID was diagnosed in 9/40 (22.5\%) cases, including 4 cases of PNP, 2 cases of AIHA, and 1 case each of SS, MG, and psoriasis, with different sequence of onset - the diagnosis of SS and psoriasis were made preceded iMCD; AIHA in 2 iMCD patients and PNP in $3 \mathrm{UCD}$ and $1 \mathrm{iMCD}$ patients were diagnosed contemporaneously with $\mathrm{CD}$; besides, $\mathrm{MG}$ occurred following the removal of tumor mass in one case with UCD (Table 1). The occurrence of AID in patients with MCD was higher than that in patients with UCD with no significant difference (33.3\% vs. $16 \%, p=0.255)$.

\section{Clinical characteristics of CD patients with AID}

Clinical features of CD patients complicated with AID are illustrated in Table 2. The median age of the cohort was $36(16-59)$ years. Of the 9 patients, $48 \%$ were male, and $55.6 \%$ had MCD. The histology was PC variant in five cases and HV variant in four cases. Systemic manifestations were common in them. Multicentric lymphadenopathy was reported in $55.6 \%$ patients. The next frequently clinical features included B symptoms $(33.3 \%)$, hepatomegaly and splenomegaly (22.2\%), and edema, ascites, or pleural effusion $(11.1 \%)$. No significant difference was observed in sex, age, clinical and pathological type of $\mathrm{CD}$, and systemic manifestations for those patients as compared to those without AID $(p>0.05)$.

Furthermore, by analyzing damage or dysfunction of specific organs or systems, it was found that the majority of patients with AID presented with skin and/or mucous membrane damage. Especially, extensive and refractory mucositis favoring the tongue and the labial and buccal mucosa was found in all four CD patients with PNP. In addition, nearly half of CD patients with AID presented pulmonary complications. Dyspnea caused by severe obstructive ventilation dysfunction and respiratory muscle paralysis occurred in CD patients with PNP, SS, and MG. Besides, general weakness due to positive antibody against acetylcholine receptor and severe nervous injury developed in the case of CD with MG. No renal impairment was observed. Compared with those without AID, CD patients with AID were more likely to have skin and/ or mucous membrane damage $(77.8 \%$ vs. $6.5 \%, p<0.001)$, and pulmonary complications $(55.6 \%$ vs. $6.5 \%, p=0.003)$ (Table 2).

Table 1 The prevalence of AID in CD patients with different sequence of onset

\begin{tabular}{llllll}
\hline $\begin{array}{l}\text { Types of } \\
\text { AID }\end{array}$ & $\begin{array}{l}\text { UCD } \\
(n=4)\end{array}$ & $\begin{array}{l}\text { MCD } \\
(n=5)\end{array}$ & $\begin{array}{l}\text { AID } \\
\text { occurred } \\
\text { preceded } \\
\text { CD } \\
(n=2)\end{array}$ & $\begin{array}{l}\text { AID } \\
\text { occurred } \\
\text { concur- } \\
\text { rently } \\
\text { with CD } \\
(n=6)\end{array}$ & $\begin{array}{l}\text { AID } \\
\text { occurred } \\
\text { after CD } \\
(n=1)\end{array}$ \\
\hline SS & & 1 & 1 & & \\
psoriasis & & 1 & 1 & & \\
AIHA & & 2 & & 2 & 1 \\
PNP & 3 & 1 & & 4 & \\
MG & 1 & & & & \\
\hline
\end{tabular}

$A I D$ autoimmune diseases, $C D$ Castleman disease, $U C D$ unicentric $\mathrm{CD}, M C D$ multicentric CD, SS Sjogren's syndrome, AIHA autoimmune hemolytic anemia; $P N P$ Paraneoplastic pemphigus, $M G$ myasthenia gravis 
Table 2 Comparison of clinical characteristics between $\mathrm{CD}$ patients with $\operatorname{AID}(n=9)$ and without AID $(n=31)$

\begin{tabular}{lllr}
\hline Characteristics & $\begin{array}{l}\text { CD with AID } \\
(n=9)\end{array}$ & $\begin{array}{l}\text { CD without AID } \\
(n=31)\end{array}$ & $p$ value \\
\hline Sex & & & 1.000 \\
Male, $n(\%)$ & $5(55.6)$ & $17(54.8)$ & \\
Female, $n(\%)$ & $4(44.4)$ & $14(45.2)$ & 0.172 \\
Median age (range) & $36(16-59)$ & $43(15-80)$ & 0.255 \\
Clinical type & & & \\
UCD, $n(\%)$ & $4(44.4)$ & $21(67.7)$ & 0.255 \\
MCD, $n(\%)$ & $5(55.6)$ & $10(32.3)$ & \\
Pathological type & & $21(67.7)$ & $10(32.3)$ \\
Hyaline vascular, $n(\%)$ & $4(44.4)$ & & 0.348 \\
Plasma cell, $n(\%)$ & $5(55.6)$ & $5(16.1)$ & 0.255 \\
Systemic manifestations & & $10(32.3)$ & 1.000 \\
Night sweats, fever, and weight loss, $n(\%)$ & $3(33.3)$ & $8(25.8)$ & 1.000 \\
Multicentric lymphadenopathy, $n(\%)$ & $5(55.6)$ & $4(12.9)$ & \\
Hepatomegaly and/or splenomegaly, $n(\%)$ & $2(22.2)$ & & 0.001 \\
Edema, ascites, or pleural effusion, $n(\%)$ & $1(11.1)$ & $2(6.5)$ & 0.404 \\
Organ dysfunction & & $1(3.2)$ & 0.557 \\
Skin and mucous membrane damage, $n(\%)$ & $7(77.8)$ & $2(6.5)$ & \\
Nervous and muscle injury, $n(\%)$ & $1(11.1)$ & & \\
Renal impairment, $n(\%)^{\mathrm{a}}$ & & & \\
Pulmonary complications, $n(\%)^{\mathrm{b}}$ & $5(55.6)$ & & \\
\hline
\end{tabular}

$C D$ Castleman disease, $A I D$ autoimmune diseases, $U C D$ unicentric $\mathrm{CD}, M C D$ multicentric $\mathrm{CD}$

${ }^{a}$ Elevated serum creatinine levels above the reference range or proteinuria above $3.5 \mathrm{~g} / 24 \mathrm{~h}$

${ }^{\mathrm{b}}$ Including pulmonary infiltrates, restrictive lung disease, lymphoid interstitial pneumonitis, and obliterative bronchiolitis

\section{Laboratory features of CD patients with AID}

Laboratory data for CD patients complicated with AID is illustrated in Table 3. Anemia was found in $44.4 \%$ patients. Thrombocytosis was seen in $22.2 \%$ cases, whereas no thrombocytopenia was noted. Besides, $66.7 \%$ patients had elevated levels of ESR, and $44.4 \%$ cases had elevated levels of CRP, RF and ASO elevated in $22.2 \%$ patients, respectively. Hypergammaglobulinaemia was recorded in $66.7 \%$ individuals. Moreover, autoantibodies including ANA,
Table 3 Comparison of laboratory abnormalities between CD patients with AID $(n=9)$ and without AID $(n=31)$

\begin{tabular}{llll}
\hline Variable & $\begin{array}{l}\text { CD with AID } \\
(n=9)\end{array}$ & $\begin{array}{l}\text { CD without AID } p \text { value } \\
(n=31)\end{array}$ \\
\hline Anemia $(<125 \mathrm{~g} / \mathrm{l}$ for males, $<115 \mathrm{~g} / \mathrm{l}$ for females $), n(\%)$ & $4(44.4)$ & $10(32.3)$ & 0.694 \\
Thrombocytosis $\left(>300 \times 10^{9} / \mathrm{l}\right), n(\%)$ & $2(22.2)$ & $6(19.4)$ & 1.000 \\
Thrombocytopenia $\left(<125 \times 10^{9} / \mathrm{l}\right), n(\%)$ & $0(0)$ & $3(9.7)$ & 1.000 \\
Elevated ESR $(>20 \mathrm{~mm} / \mathrm{h}), n(\%)$ & $6(66.7)$ & $7(22.6)$ & 0.038 \\
Elevated CRP $(>10 \mathrm{mg} / \mathrm{l}), n(\%)$ & $4(44.4)$ & $7(22.6)$ & .227 \\
Elevated RF $(>30 \mathrm{IU} / \mathrm{ml}), n(\%)$ & $2(22.2)$ & $0(0)$ & 0.225 \\
Elevated ASO $(>200 \mathrm{IU} / \mathrm{ml}), n(\%)$ & $2(22.2)$ & $4(12.9)$ & 0.602 \\
Hypergammaglobulinemia, $n(\%)$ & $6(66.7)$ & $8(25.8)$ & 0.044 \\
Positivity of autoantibodies, $n(\%)$ & $5(55.6)$ & $5(16.1)$ & 0.029 \\
Positive ANA, ds-DNA, ENA, ANCA and/or ACA, $n(\%)$ & $4(44.4)$ & $4(12.9)$ & 0.059 \\
Positive coombs test, $n(\%)$ & $3(33.3)$ & $2(6.5)$ & 0.065 \\
\hline
\end{tabular}

$C D$ Castleman disease, $A I D$ autoimmune diseases, $U C D$ multicentric $\mathrm{CD}, M C D$ unicentric $\mathrm{CD}, E S R$ erythrocyte sedimentation rate, $C R P$ C-reactive protein, $R F$ Rheumatoid factor, ASO Anti-streptolysin O, ANA antinuclear antibody, $d s-D N A$ double stranded antinuclear antibody, ENA extractable nuclear antigen polypeptide antibodies, $A N C A$ antineutrophil cytoplasmic antibody, $A C A$ anticardiolipin antibody 
ds-DNA, ENA, ANCA and ACA were positive in 44.4\% patients, and Coombs test was positive in ${ }^{`} 33.3 \%$ cases.

Compared with those without AID, CD patients with AID showed higher incidence of elevated ESR (66.7\% vs. $22.6 \%, p=0.038)$ and hypergammaglobulinemia (66.7\% vs. $25.8 \%, p=0.044)$. Additionally, a significant higher rate of positive ANA, ds-DNA, ENA, ANCA, ACA and/or positive coombs test was observed in them ( $55.6 \%$ vs. $16.1 \%$, $p=0.029$ ). (Table 3).

\section{Immune function monitoring}

To further understand the immune pathogenesis of CD accompanied by AID, we analyzed the change of peripheral lymphocyte subsets in $6 \mathrm{CD}$ patients with AID and 12 patients without AID at the diagnosis of $\mathrm{CD}$.

As shown in Table 4, a significant lower proportion of $\mathrm{CD}^{+} \mathrm{T}$ cells $(64.8 \pm 11.4 \%$ vs. $74.6 \pm 8.5 \%, p=0.033)$ and a higher proportion of NK cells $(25.7 \pm 12.7 \%$ vs $11.7 \pm 4.4 \%$, $p=0.028$ ) were observed in patients with AID. A tendency of fewer $\mathrm{CD}^{+} \mathrm{T}$ cells $(29.6 \pm 10.0 \%$ vs. $37.1 \pm 7.0 \%$,

Table 4 Distribution of lymphocyte populations in peripheral blood of CD patients with AID $(n=6)$ and without AID $(n=12)$

\begin{tabular}{lccc}
\hline Lymphocyte subsets & CD with AID $(n=6)$ & $\begin{array}{c}\text { CD without } \\
\text { AID }(n=12)\end{array}$ & $p$ value \\
\hline $\mathrm{CD}^{+}$T cells (\%) & $64.8 \pm 11.4$ & $74.6 \pm 8.5$ & 0.033 \\
$\mathrm{CD}^{+} \mathrm{T}$ cells (\%) & $29.6 \pm 10.0$ & $37.1 \pm 7.0$ & 0.062 \\
$\mathrm{CD}^{+} \mathrm{T}$ cells (\%) & $31.9 \pm 9.5$ & $35.8 \pm 12.1$ & 0.483 \\
$\mathrm{CD} 4^{+}: \mathrm{CD} 8^{+}$ratio & $1.0 \pm 0.6$ & $1.2 \pm 0.8$ & 0.773 \\
$\mathrm{~B}$ cells $(\%)$ & $7.9 \pm 6.1$ & $10.34 \pm 2.8$ & 0.289 \\
Nature killer cells $(\%)$ & $25.7 \pm 12.7$ & $11.7 \pm 4.4$ & 0.028 \\
\hline
\end{tabular}

$C D$ Castleman disease, $A I D$ autoimmune diseases $p=0.062$ ) was also observed in cases with AID. However, no significant difference in the percentage of $\mathrm{CD}^{+} \mathrm{T}$ cells and $\mathrm{B}$ cells subsets was found in two groups. The $\mathrm{CD} 4^{+}$: $\mathrm{CD}^{+}$ratio was not significantly lower in patients with AID.

\section{Treatment and outcomes}

Treatment of CD complicated with AID was mainly based on the clinical type of CD (Table 5).

Except one UCD patient with PNP (no. 1) was cured by tumor excision, other 3 patients with PNP and CD (no. 2, $3,4)$ accepted effective immunosuppressive therapy with corticosteroid (GC), methotrexate (MTX), and intravenous immune globulin (IVIG) perioperatively. Unfortunately, one among them (no. 4) relapsed with severe oral mucositis and pulmonary destruction leading to obliterative bronchiolitis (OB) after treatment. Pulmonary injury with respiratory failure was relieved with IVIG again. Thalidomide and oral methylprednisolone were adopted for maintenance therapy. It should be alerted that, one UCD patient (no. 5) with mediastinal UCD, HV type, experienced a postoperative myasthenic crisis after tumor and thymus excision. His general condition improved soon with pyridostigmine bromide and methyl-prednisolone.

Symptoms of MCD patient with co-existing SS (no. 6) was improved with immunosuppressive agents (GC, azathioprine, hydroxychloroquine, and total glycosides of paeony). Rituximab in combination with cytotoxic chemotherapy was effective in one patient with MCD and associated AIHA (no. 7), but failed in another case with the same diagnosis (no. 8). This patient took oral cyclophosphamide-prednisone-thalidomide (CPT) regimen subsequently, improvement of anemia was observed. Besides, MCD occurred following Psoriasis was relieved with combination chemotherapy followed by maintenance therapy with thalidomide (no. 9).

Table 5 Treatment and outcomes of CD complicated with AID

\begin{tabular}{|c|c|c|c|c|c|}
\hline No. & Sex, age & CD typing & AID & Treatment & Outcomes \\
\hline 1 & $\mathrm{~F}, 31$ & HV UCD & PNP & Tumor excision & Remission \\
\hline 2 & M, 18 & HV UCD & PNP & Tumor excision, GC, MTX, IVIG & Remission \\
\hline 3 & $\mathrm{~F}, 31$ & PC MCD & PNP & Tumor excision, GC, MTX & Remission \\
\hline 4 & $\mathrm{~F}, 16$ & HV UCD & PNP\&OB & Tumor excision, GC, MTX, IVIG, Aza, thalidomide & Relapse \\
\hline 5 & M, 37 & HV UCD & MG & Tumor and thymus excision, pyridostigmine bromide, GC & Remission \\
\hline 6 & $\mathrm{~F}, 46$ & PC MCD & SS & GC, Aza, hydroxychloroquine, TGP & Remission \\
\hline 7 & M, 46 & PC MCD & AIHA & R-CHOP & Remission \\
\hline 8 & M, 44 & PC MCD & AIHA & R-CHOP, R-MINE, CPT & Remission \\
\hline 9 & M, 59 & PC MCD & Psoriasis & COP, thalidomide & Remission \\
\hline
\end{tabular}

$C D$ Castleman disease, $A I D$ autoimmune diseases, $M$ male, $F$ female, $H V$ hyaline vascular, $P C$ plasma cell, $U C D$ unicentric $C D, M C D$ multicentric CD, SS Sjogren's syndrome, $A I H A$ autoimmune hemolytic anemia, $P N P$ Paraneoplastic pemphigus, $O B$ obliterative bronchiolitis, $M G$ myasthenia gravis, $G C$ glucocorticoid, $M T X$ methotrexate, IVIG intravenous immune globulin, Aza azathioprine, TGP total glycosides of paeony, $R$ rituximab, $C H O P$ cyclophosphamide/vincristine/Adriamycin/prednisone, MINE mitoxantrone/ifosfamide/etoposide, $C P T$ cyclophosphamide/ prednisone/thalidomide, $C O P$ cyclophosphamide/vincristine/prednisone 


\section{Discussion}

To make an early and timely diagnosis of CD complicated with AID, we explored the prevalence of AID in a small population of patients with lymph node histopathological findings consistent with CD. AID was found to be coexisted with CD in 99/40 (22.5\%) patients, a higher proportion than expected. Among them, PNP was most commonly observed. PNP is a mucocutaneous disease due to immunological effects of an obvious or occult lymphoproliferative disorder in most cases (Bin et al. 2019; Kartan et al. 2017; Sehgal and Srivastava 2009). CD constitute nearly $18.4 \%$ of hematologic neoplasms/disorderrelated PNP (Sehgal and Srivastava 2009). We described four cases with CD associated PNP, and OB as a common and fatal compilation was noted in one of them. The second common AID associated with CD observed in our study was AIHA, which has been reported to be occasionally associated with MCD, although positive coombs test was more prevalent in this population (Liu et al. 2016). Besides, CD was also found to be complicated with SS in the present study. SS has also been described coexisting with $\mathrm{CD}$ in a few case reports, and CD may be a lymphoproliferative disorder associated with SS (Dei-Adomakoh et al. 2018). CD associated with $M G$ is especially rare (Lee et al. 2012). This study described a postoperative myasthenic crisis in one patient with mediastinal UCD, HV type, which has been reported (Ishikawa et al. 2014). CD complicated by psoriasis observed in this study has not been reported. It should be noted that, AID may occur before, concurrent with, or after the diagnosis of CD, possibly with distinctive pathophysiology (Muskardin et al. 2012; Marchi et al. 2004).

We further explored the clinical characteristics of CD complicated with AID. No bias for the clinical and histological type of $\mathrm{CD}$ was observed for the occurrence of AID. Although MCD was found to be the form of CD, most frequently accompanied by symptoms and signs of autoimmunity in previous reports, and iMCD has a close association with several autoimmune and autoinflammatory diseases, UCD with localized lesions and less systematic syndromes could also be occasionally complicated with diverse autoimmune disorders (Muskardin et al. 2012; Fajgenbaum et al. 2014; Liu et al. 2016). Consistent with previous reports, AIHA and SS occurred in cases with PC variant, and MG in HV variant in this study (Yuzuriha et al. 2011; Tabata et al. 2019; Dei-Adomakoh et al. 2018; Ishikawa et al. 2014). In addition, the majority of PNP in our study was associated with HV type UCD as reported (Nikolskaia et al. 2003). An association between CD accompanied by AID and both systemic inflammation/ immunological abnormalities and organ dysfunction was supported by our data. Compared with CD patients without AID, those with AID were more likely to have rash, mucous injury, and pulmonary complications. Moreover, elevated inflammatory markers ESR, hypergammaglobulinemia, and positive autoantibodies were more commonly observed in them. Hence, if rash, mucosal lesions, dyspnea, hypergammaglobulinemia or positive autoantibodies are present, further evaluation is required to exclude coexisting PNP, OB, and other autoimmune disorders in CD patients.

Mechanism for the coexistence of $\mathrm{CD}$ and autoimmune disorders in the same patient remained unclear. They likely share same features of pathophysiology. IMCD is speculated to manifest episodic systemic inflammatory symptoms, reactive proliferation of morphologically benign lymphocytes, and multiple-organ system impairment as a result of excessive interleukin-6 (IL-6) and other proinflammatory cytokines (Fajgenbaum et al. 2014). IL-6, as a multifunctional cytokine, may be responsible for autoimmune phenomena in iMCD by inducing the production of autoantibody and the expansion of autoantibody producing $\mathrm{CD}^{+}$B lymphocytes (Yoshizaki et al. 2018). Besides, IL-6 could also dysregulate the cellular immune response by inducing proliferation and differentiation of $\mathrm{T}$ cells (Kimura and Kishimoto 2010). This study investigated the cellular immune dysfunction by monitoring $\mathrm{T}$ cell subsets, and showed a significant decrease of $\mathrm{CD}^{+} \mathrm{T}$ cells and a tendency of fewer $\mathrm{CD}^{+}{ }^{+} \mathrm{T}$ cells in peripheral blood of $\mathrm{CD}$ patients complicated with AID, indicating deregulated cellular immune responses, possible induced by IL-6, may be involved in its pathogenesis. Thus, impairment of cellular immune mechanisms, claimed to be an important determinant of the autoimmune complications in chronic lymphocytic leukemia (Hodgson et al. 2011) could operate in CD as well. In addition, increased NK cells observed in these patients suggested alterations in the innate immune system may also participant in the development of autoimmunity. Consistently, PNP which is associated with occult or confirmed hematologic and nonhematologic neoplasms may not be the result solely of a humoral response, autoreactive cellular autotoxicity mediated by $\mathrm{CD} 8^{+}$cytotoxic $\mathrm{T}$ lymphocytes, $\mathrm{CD} 6^{+} \mathrm{NK}$ cells, and $\mathrm{CD} 68^{+}$macrophages may also be implicated (Sehgal and Srivastava 2009).

It should be reminded that the biological mechanism for the frequency of autoimmunity in CD maybe complex. Evidence has been slowly accumulating for the role of additional cytokines, such as B-lymphocyte stimulator (BLyS), in the coexistence of AID and CD (Muskardin et al. 2012; Marchi et al. 2004). Better understanding of pathogenic cell types and cytokines will shed new light on its intricate pathogenesis. In addition, it is not clear if autoimmunity is the underlying cause or result of $\mathrm{CD}$. Some autoimmune complications are known downstream complications of $\mathrm{CD}$, 
such as PNP, AIHA, and MG, and some others are known upstream complications, such as SLE, SS, and RA, making CD a secondary disease (Muskardin et al. 2012; Marchi et al. 2004; Fajgenbaum et al. 2017). To clarify the distinctive pathophysiology between them, more efforts are needed to classify autoimmunity as downstream or upstream autoimmune diseases and analyze each group separately.

Understanding in CD and associated connective tissue diseases has allowed the development of targeted therapies. This study showed that UCD patients complicated with AID could be successfully treated with surgical excision of the tumor mass and immunosuppressive therapy. However, one case with PP and UCD relapsed with OB as a pulmonary compilation after treatment. Since perioperative immunosuppressive therapy is necessary to prevent fatal pulmonary injury in patients with CD and PNP (Nikolskaia et al. 2003), sustained and more powerful immunosuppressive treatment post-surgery might be needed for this patient. It should be alerted that, a rare postoperative myasthenic crisis may occur after the removal of tumor in patients with mediastinal solitary $\mathrm{CD}$, early diagnosis guaranteed effective treatment in this study.

Currently, corticosteroids and/or combination chemotherapy were the most common interventions selected for patients with MCD (Liu et al. 2016). In this study, autoimmune manifestations relieved with immunosuppressors and cytotoxic chemotherapy in MCD patients with SS and Psoriasis, respectively. In addition, rituximab has also been effective for autoimmune cytopenia, with or without associated lymphoproliferative disorders, and may be particularly useful in patients with AID associated with MCD (Muskardin et al. 2012; Ocio et al. 2005). In this study, multidrug chemotherapy combined with rituximab was proved to be effective in one of the two MCD patients with AIHA. In another case with iMCD and AIHA, CPT regimen showed promising efficacy and safety as reported (Zhang et al. 2019). Besides, IL-6-based therapies have shown marked benefit in MCD and in a variety of AID. Treatment with Tocilizumab, a humanized anti-IL-6 receptor monoclonal antibody, resulted in either resolution or improvement of both CD and the AID (Yuzuriha et al. 2011; Dispenzieri and Fajgenbaum 2020). Hence, treatments that target pathogenic cell types, cytokines, or pathways that are shared in CD and associated AID would be more successful in the future.

Admittedly, cautious interpretation of our results is warranted because of several limitations of our retrospective study. Most importantly, we analyzed a small sample, sometimes with incomplete data. As a result, analyses were probably underpowered to identify the clinical and biological characteristics associated with AID in CD patients. Also, AID associated with CD are highly heterogeneous. Limited samples in this study constrained an in-depth analysis of the pathogenesis in patients with $\mathrm{CD}$ preceded or occurred contemporaneously with AID and those with AID preceded $\mathrm{CD}$ to clarify the distinctive pathophysiology between them.

In conclusion, this study analyzed the prevalence of AID in the cohort of CD patients, and identified systemic inflammation/immunological abnormalities and organ dysfunction associated with autoimmunity in CD. Impairment of cellular and innate immunity mechanisms may be a candidate etiology for the coexistence of the two entities. Early identification of CD and associated AID will guarantee more successful treatments.

Acknowledgements None.

Author contributions JYL, WX, and DPS were responsible for the study concept and design. DPS, WMC, LW, ZW, JHL, HYZ, LF, and YJW contributed to the data collection and data analysis. DPS and WMC analyzed the data and wrote the initial draft. JYL and WX critically reviewed the manuscript. All authors read and approved the final version of the manuscript.

Funding This study was supported by National Natural Science Foundation of China (81720108002), Jiangsu Province's Medical Elite Program (ZDRCA2016022), Jiangsu Provincial Special Program of Medical Science (BE2017751), National Science and Technology Major Project (2018ZX09734007), Science and Technology Development Projects of Jining City (2016-56-25), and Key research and development projects of Jining City (2018SMNS008 and 2019SMNS007).

Availability of data and materials The datasets used and/or analyzed during the current study are available from the corresponding author on reasonable request. Code availability not applicable.

\section{Compliance with ethical standards}

Conflict of interest All authors declare that they have no competing interests.

Ethics approval and consent to participate This single-center retrospective study was approved by the Ethics Committee of the First Affiliated Hospital of Nanjing Medical University. The need for informed consent was waived by the committee.

Open Access This article is licensed under a Creative Commons Attribution 4.0 International License, which permits use, sharing, adaptation, distribution and reproduction in any medium or format, as long as you give appropriate credit to the original author(s) and the source, provide a link to the Creative Commons licence, and indicate if changes were made. The images or other third party material in this article are included in the article's Creative Commons licence, unless indicated otherwise in a credit line to the material. If material is not included in the article's Creative Commons licence and your intended use is not permitted by statutory regulation or exceeds the permitted use, you will need to obtain permission directly from the copyright holder. To view a copy of this licence, visit http://creativecommons.org/licenses/by/4.0/. 


\section{References}

Aletaha D, Neogi T, Silman AJ, Funovits J, Felson DT, Bingham CO 3rd, Birnbaum NS, Burmester GR, Bykerk VP, Cohen MD, Combe B, Costenbader KH, Dougados M, Emery P, Ferraccioli G, Hazes JMW, Hobbs K, Huizinga TWJ, Kavanaugh A, Kay J, Kvien TK, Laing T, Mease P, Ménard HA, Moreland LW, Naden RL, Pincus T, Smolen JS, Stanislawska-Biernat E, Symmons D, Tak PP, Upchurch KS, Vencovsky J, Wolfe F, Hawker G (2010) 2010 rheumatoid arthritis classification criteria: an American College of Rheumatology/European League Against Rheumatism collaborative initiative. Ann Rheum Dis 69:1580-1588. https://doi. org/10.1002/art.27584

Ben-Chetrit E, Flusser D, Okon E, Ackerman Z, Rubinow A (1989) Multicentric Castleman's disease associated with rheumatoid arthritis: a possible role of hepatitis B antigen. Ann Rheum Dis 48:326-330. https://doi.org/10.1136/ard.48.4.326

Bin Waqar SH, Khan AA, Mohiuddin O, Rehan A (2019) Paraneoplastic pemphigus with underlying Castleman's disorder: a rare report with literature review. Cureus 11:e5022. https://doi.org/10.7759/ cureus.5022

Dei-Adomakoh YA, Quarcoopome L, Abrahams AD, Segbefia CI, Dey DI (2018) Sjogren's and plasma cell variant Castleman disease: a case report. Ghana Med J 52:61-65. https://doi.org/10.4314/ gmj.v52i1.9

Dispenzieri A, Fajgenbaum DC (2020) Overview of Castleman disease. Blood 135:1353-1364. https://doi.org/10.1182/blood.2019000931

Fajgenbaum DC, Shilling D (2018) Castleman disease pathogenesis. Hematol Oncol Clin N Am 32:11-21. https://doi.org/10.1016/j. hoc.2017.09.002

Fajgenbaum DC, Rhee FV, Nabel CS (2014) HHV-8-negative, idiopathic multicentric Castleman disease: novel insights into biology, pathogenesis, and therapy. Blood 123:2924-2933. https://doi. org/10.1182/blood-2013-12-545087

Fajgenbaum DC, Uldrick TS, Bagg A, Frank D, Wu D, Srkalovic G, Simpson D, Liu AY, Menke D, Chandrakasan S, Lechowicz MJ, Wong RSM, Pierson S, Paessler M, Rossi JF, Ide M, Ruth J, Croglio M, Suarez A, Krymskaya A, Chadburn A, Colleoni G, Nasta S, Jayanthan R, Nabel CS, Casper C, Dispenzieri A, Fosså A, Kelleher D, Kurzrock R, Voorhees P, Dogan A, Yoshizaki K, Rhee FV, Oksenhendler E, Jaffe ES, Elenitoba-Johnson KSJ, Lim MS (2017) International, evidence-based consensus diagnostic criteria for HHV-8-negative/idiopathic multicentric Castleman disease. Blood 129:1646-1657. https://doi.org/10.1182/blood -2016-10-746933

Hehir MK, Silvestri NJ (2018) Generalized myasthenia gravis: classification, clinical presentation, natural history, and epidemiology. Neurol Clin 36:253-260. https://doi.org/10.1016/j. ncl.2018.01.002

Hodgson K, Ferrer G, Montserrat E, Moreno C (2011) Chronic lymphocytic leukemia and autoimmunity: a systematic review. Haematologica 96:752-761. https://doi.org/10.3324/haema tol.2010.036152

Ishikawa K, Kato T, Aragaki M, Ohbuchi T, Kimura S, Matsui Y, Kaji M (2014) A case of Castleman's disease with myasthenia gravis. Ann Thorac Cardiovasc Surg 20:585-588. https://doi.org/10.5761/ atcs.cr.12.02165

Kartan S, Shi VY, Clark AK, Chan LS (2017) Paraneoplastic pemphigus and autoimmune blistering diseases associated with neoplasm: characteristics, diagnosis, associated neoplasms, proposed pathogenesis, treatment. Am J Clin Dermatol 18:105-126. https://doi. org/10.1007/s40257-016-0235-z

Keller AR, Hochholzer L, Castleman B (1972) Hyaline-vascular and plasma-cell types of giant lymph node hyperplasia of the mediastinum and other locations. Cancer 29:670-683. https:// doi.org/10.1002/1097-0142(197203)29:3<670::aid-cncr282029 $0321>3.0 . c 0 ; 2-\#$

Kimura A, Kishimoto T (2010) IL-6: regulator of Treg/Th17 balance. Eur J Immunol 40:1830-1835. https://doi.org/10.1002/eji.20104 0391

Kojima M, Nakamura S, Morishita Y, Itoh H, Yoshida K, Ohno Y, Oyama T, Asano S, Joshita T, Mori S, Suchi T, Masawa N (2000) Reactive follicular hyperplasia in the lymph node lesions from systemic lupus erythematosus patients: a clinicopathological and immunohistological study of 21 cases. Pathol Int 50:304-312. https://doi.org/10.1046/j.1440-1827.2000.01052.x

Kojima M, Motoori T, Nakamura S (2006) Benign, atypical and malignant lymphoproliferative disorders in rheumatoid arthritis patients. Biomed Pharmacother 60:663-672. https://doi. org/10.1016/j.biopha.2006.09.004

Lee SK, Kim DH, Son BS (2012) Castleman's disease with myasthenia gravis. Korean J Thorac Cardiovasc Surg 45:199-201. https://doi. org/10.5090/kjtcs.2012.45.3.199

Liu AY, Nabel CS, Finkelman BS, Ruth JR, Kurzrock R, Rhee FV, Krymskaya VP, Kelleher D, Rubenstein AH, Fajgenbaum DC (2016) Idiopathic multicentric Castleman's disease: a systematic literature review. Lancet Haematol 3:e163-175. https://doi. org/10.1016/S2352-3026(16)00006-5

London J, Boutboul D, Agbalika F, Coppo P, Veyradier A, Gérard L, Oksenhendler E, Azoulay E, Galicier L (2017) Autoimmune thrombotic thrombocytopenic purpura associated with HHV8related Multicentric Castleman disease. Br J Haematol 178:486488. https://doi.org/10.1111/bjh.14152

Marchi GD, Vita SD, Fabris M, Scott CA, Ferraccioli G (2004) Systemic connective tissue disease complicated by Castleman's disease: report of a case and review of the literature. Haematologica 89:ECR03

Muskardin TW, Peterson BA, Molitor JA (2012) Castleman disease and associated autoimmune disease. Curr Opin Rheumatol 24:76-83. https://doi.org/10.1097/BOR.0b013e32834db525

Nikolskaia OV, Nousari CH, Anhalt GJ (2003) Paraneoplastic pemphigus in association with Castleman's disease. Br J Dermatol 149:1143-1151. https://doi.org/10.1111/j.1365-2133.2003.05659 .X

Ocio EM, Sanchez-Guijo FM, Diez-Campelo M, Castilla C, Blanco OJ, Caballero D, Miguel JFS (2005) Efficacy of rituximab in an aggressive form of multicentric Castleman disease associated with immune phenomena. Am J Hematol 78:302-305. https:// doi.org/10.1002/ajh.20283

Ogita M, Hoshino J, Sogawa Y, Sawa N, Katori H, Takemoto F, Ubara Y, Hara S, Miyakoshi S, Takaichi K (2007) Multicentric Castleman disease with secondary AA renal amyloidosis, nephrotic syndrome and chronic renal failure, remission after high-dose melphalan and autologous stem cell transplantation. Clin Nephrol 68:171-176. https://doi.org/10.5414/cnp68171

Petri M, Orbai AM, Alarcón GS, Gordon C, Merrill JT, Fortin PR, Bruce IN, Isenberg D, Wallace DJ, Nived O, Sturfelt G, Ramsey-Goldman R, Bae SC, Hanly JG, Sánchez-Guerrero J, Clarke A, Aranow C, Manzi S, Urowitz M, Gladman D, Kalunian K, Costner M, Werth VP, Zoma A, Bernatsky S, Ruiz-Irastorza G, Khamashta MA, Jacobsen S, Buyon JP, Maddison P, Dooley MA, Vollenhoven RFV, Ginzler E, Stoll T, Peschken C, Jorizzo JL, Callen JP, Lim SS, Fessler BJ, Inanc M, Kamen DL, Rahman A, Steinsson K, Sigler L, Hameed S, Fang H, Pham N, Brey R, Weisman MH, Magder LS (2012) Derivation and validation of the Systemic Lupus International Collaborating Clinics classification criteria for systemic lupus erythematosus. Arthritis Rheum 64:2677-2686. https://doi.org/10.1002/art.34473

Raychaudhuri SK, Maverakis E, Raychaudhuri SP (2014) Diagnosis and classification of psoriasis. Autoimmun Rev 13:490-495. https ://doi.org/10.1016/j.autrev.2014.01.008 
Sehgal VN, Srivastava G (2009) Paraneoplastic pemphigus/paraneoplastic autoimmune multiorgan syndrome. Int J Dermatol 48:162169. https://doi.org/10.1111/j.1365-4632.2009.03995.x

Sève P, Philippe P, Dufour JF, Broussolle C, Michel M (2008) Autoimmune hemolytic anemia: classification and therapeutic approaches. Expert Rev Hematol 1:189-204. https://doi. org/10.1586/17474086.1.2.189

Stefanski AL, Tomiak C, Pleyer U, Dietrich T, Burmester GR, Dörner T (2017) The diagnosis and treatment of Sjogren's syndrome. Dtsch Arztebl Int 114:354-361. https://doi.org/10.3238/arzte bl.2017.0354

Tabata S, Higuchi T, Tatsukawa S, Narimatsu K, Takeo H, Matsukuma $\mathrm{S}$, Ito T (2019) Idiopathic multicentric Castleman disease with autoimmune hemolytic anemia and production of anti-drug antibody against tocilizumab. Intern Med 58:3313-3318. https://doi. org/10.2169/internalmedicine.2989-19

Wang L, Chen H, Shi J, Tang H, Li H, Zheng WJ, Zhang FC (2018) Castleman disease mimicking systemic lupus erythematosus: a case report. Medicine (Baltimore) 97:e12291. https://doi. org/10.1097/MD.0000000000012291
Yoshizaki K, Murayama S, Ito H, Koga T (2018) The role of interleukin-6 in Castleman disease. Hematol Oncol Clin N Am 32:23-36. https://doi.org/10.1016/j.hoc.2017.09.003

Yuzuriha A, Saitoh T, Koiso H, Mitsui T, Uchiumi H, Yokohama A, Handa H, Kojima M, Tsukamoto N, Karaswa M, Murakami H, Nojima Y (2011) Successful treatment of autoimmune hemolytic anemia associated with multicentric Castleman disease by antiinterleukin-6 receptor antibody (tocilizumab) therapy. Acta Haematol 126:147-150. https://doi.org/10.1159/000328426

Zhang L, Zhao AL, Duan MH, Li ZY, Cao XX, Feng J, Zhou DB, Zhong DR, Fajgenbaum DC, Li J (2019) Phase 2 study using oral thalidomide-cyclophosphamide-prednisone for idiopathic multicentric Castleman disease. Blood 133:1720-1728. https:// doi.org/10.1182/blood-2018-11-884577

Publisher's Note Springer Nature remains neutral with regard to jurisdictional claims in published maps and institutional affiliations. 